\title{
Organometallic Coordination Networks Based on $\pi$-Bonded Transition Metal Quinonoid Complexes
}

\author{
Jeffrey A. Reingold, ${ }^{1}$ Seung Uk Son, ${ }^{2}$ Gene B. Carpenter, ${ }^{1}$ and Dwight A. Sweigart ${ }^{1,3}$
}

ERRATUM TO: JOURNAL OF INORGANIC

AND ORGANOMETALLIC POLYMERS AND

MATERIALS, VOL. 16, NO. 1

DOI 10.1007/s10904-006-9024-0

The submitted and accepted dates for this paper were inadvertently omitted. The dates are as follows: Submitted October 21, 2005; accepted October 25, 2005

The online version of the original article can be found at http:// dx.doi.org/10.1007/s10904-006-9024-0.

${ }^{1}$ Department of Chemistry, Brown University, Providence, RI, 02912, USA.

2 Department of Chemistry, Sungkyunkwan University, Suwon, 440-746, Korea.

${ }^{3}$ To whom correspondence should be addressed.

E-mail: dwight_sweigart@brown.edu 